\title{
Formation of Two 1:1 Chlorogenic Acid: $\beta$-cyclodextrin Complexes at pH 5: Spectroscopic, Thermodynamic and Voltammetric study ${ }^{\dagger}$
}

\author{
Emilio Álvarez-Parrilla, ${ }^{1 *}$ Ricardo Palos, ${ }^{1}$ Laura A. de la Rosa, ${ }^{1}$ Bernardo A. Frontana-Uribe, ${ }^{2}$ \\ Gustavo Adolfo González-Aguilar, ${ }^{3}$ Lorena Machi, ${ }^{4}$ Jesús Fernando Ayala-Zavala ${ }^{3}$ \\ ${ }^{1}$ Universidad Autónoma de Ciudad Juárez. Instituto de Ciencias Biomédicas. Departamento de Ciencias Básicas, \\ Tel/Fax: +52-656-688-1894, ealvarez@uacj.mx \\ 2 Centro Conjunto de Investigación en Química Sustentable. Universidad Autónoma del Estado de México-Universidad Nacional \\ Autónoma de México. Km 14.5 Carretera Toluca-Atlacomulco C.P. 50200 Toluca, Estado de México. \\ 3 Centro de Investigación en Alimentación y Desarrollo, A. C. (CIAD, AC). Carretera a la Victoria Km 0.6, La Victoria. \\ Hermosillo, Sonora (83000) México. \\ ${ }^{4}$ Departamento de Investigación en Polímeros y Materiales. Universidad de Sonora. Hermosillo, Sonora.
}

Received January 29, 2010; accepted May 10, 2010

\begin{abstract}
Complexation of chlorogenic acid (CA) by $\beta$-cyclodextrin $(\beta-\mathrm{CD})$ at mildly acidic $\mathrm{pH}$, was studied by fluorescence spectroscopy, isothermal titration calorimetry (ITC), cyclic voltammetry (CV) and NMR spectroscopy. Thermodynamic parameters $\left(\Delta H^{\circ}, \Delta S^{\circ}\right.$ and $\mathrm{K})$ determined by both fluorescence and ITC, showed that the complexation of CA by $\beta$-CD is an enthalpy-driven process. Results show that $\mathrm{CA}$ molecule can be complexed through both polyphenolic and quinic acid moiety, leading to the formation of two supramolecular isomers with 1:1 stoichiometry.

Keywords: $\beta$-cyclodextrin, chlorogenic acid, inclusion complexes, fluorescence, isothermal titration calorimetry (ITC), thermodynamic parameters.
\end{abstract}

\section{Introduction}

$\beta$-Cyclodextrin $(\beta-C D)$ is a cyclic oligomer naturally synthesized from starch, built up from 7 glucopyranose units linked by $\alpha-(1-4)$ glycosidic linkages with a truncated cone shape (Figure 1a). Due to its cyclic structure, $\beta$-CD possesses a hydrophobic cavity in which a variety of organic molecules can be trapped forming inclusion complexes. During the formation of these complexes, the physicochemical properties of the included molecule are modified; therefore, the complexation process may be useful for a number of technological applications, such as increasing the bioavailability and stability of poorly soluble drugs [1].

In the last few years, there has been an increased interest on consuming foods rich in natural antioxidants, such as fruits and vegetables, due to epidemiological studies that correlate a regular intake of these products with protection against several diseases [2]. Polyphenols are one of the main antioxidants present in fruits and vegetables; however, they present low bioavailability, due to their low absorption and solubility, as well as degradation during food processing. For these reasons,

\footnotetext{
$\dagger$ Part of this paper was presented at the 65 th Southwest Regional Meeting "Chemistry Challenges for the 21st Century" held by the American Chemical Society. El Paso, Tx, USA, November 2009.
}

Resumen. La complejación del ácido clorogénico (AC) por $\beta$-ciclodextrina $(\beta-\mathrm{CD})$ a $\mathrm{pH}$ ligeramente ácido se estudió por espectroscopia de fluorescencia, calorimetría isotérmica de titulación (CIT), voltamperometría cíclica $(\mathrm{VC})$ y RMN. Los parámetros termodinámicos del sistema $\left(\Delta H^{\circ}, \Delta S^{\circ}\right.$ and $\left.\mathrm{K}\right)$ determinados por fluorescencia e CIT sugieren que la complejación está regulada por procesos entálpicos. De los resultados obtenidos, se puede deducir que las moléculas del AC pueden ser complejadas tanto por la región fenólica como por la región quínica, dando lugar a la formación de dos isómeros supramoleculares con estequiometría $1: 1$.

Palabras claves: $\beta$-cyclodextrina, ácido clorogénico, complejos de inclusión, fluorescencia, calorimetría isotérmica de titulación, parámetros termodinámicos.

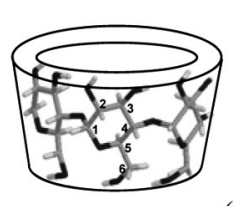

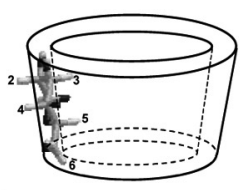

(a)

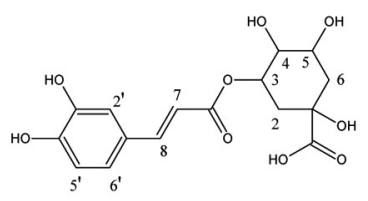

Fig. 1. Chemical structure of a) $\beta$-cyclodextrin, $\beta$-CD; b) Chlorogenic acid, CA. Numbers in both structures represent the proton numbers used in the ROESY experiments.

several papers have been published on the complexation of natural polyphenols by cyclodextrins. In these studies the complex formation has proven to be useful in enhancing the solubility and bioavailability of polyphenols [3-5], increasing their antioxidant capacity $[1,3,6,7]$ and also in protecting phenolic substrates from polyphenol oxidase (PPO), therefore reducing enzymatic browning of fresh-cut fruits and vegetables products [6-11].

Chlorogenic Acid (CA) is an ester formed between caffeic acid and quinic acid (Figure 1b), and is one of the main polyphenols found in coffee, apples and onions, as well as many other fruits and vegetables, that has been described as one of the main apple PPO substrates, and consequently, one of the main products responsible for the browning of apples products (fresh-cut apples, apple juices, apple pomace). 
In previous papers, we have reported that $\mathrm{CA}$ was complexed by $\beta-\mathrm{CD}$ at $\mathrm{pH} 7$, with a $1: 1$ stoichiometry $(\beta-\mathrm{CD}: \mathrm{CA})$, and a stability constant of $465 \mathrm{M}^{-1}$ [1]. As a result of this complexation, an increase of its antioxidant capacity was observed, probably due to the protection of the hydroxyl groups by the hydrophobic cavity.

In a second paper [8], and in agreement with several other authors, we reported that the complexation of CA by $\beta-\mathrm{CD}$ inhibited its catalytic oxidation mediated by PPO, by a mixed inhibition pattern, in which $\beta$-CD inhibited PPO activity by two possible mechanisms: i) reducing the amount of free CA that can be oxidized by the enzyme, and ii) direct interaction between PPO and $\beta-C D$ due to the complexation of hydrophobic moieties from the enzyme, resulting in a decrease of catalytic activity. The first mechanism has been wieldy described by different authors; however, the second mechanism has only been reported for horse radish peroxidase [12].

Considering that apple PPO has a $\mathrm{pH}$ dependent activity, with a maximum at near 5.0, we decided to determine the stability constant of the $\mathrm{CA}$ : $\beta$-CD complex at this $\mathrm{pH}$, in order to better understand the PPO-CA- $\beta-\mathrm{CD}$ interaction previously observed. For this reason, the aim of the present study was to determine the thermodynamic parameters, as well as possible structural conformation of the CA: $\beta-\mathrm{CD}$ complex at $\mathrm{pH} 5$. In order to carry out these studies, steady-state fluorescence spectroscopy, isothermal titration calorimetry, cyclic voltammetry and 1 and 2 dimensional ${ }^{1} \mathrm{H}$ NMR spectroscopy were carried out.

\section{Results and discussion}

\section{Thermodynamic Complexation Parameters (Steady-state Fluorescence Spectroscopy and Isothermal Titration Calorimetry)}

Series of emission spectra were recorded for solutions of the same CA concentration, with different $\beta-\mathrm{CD}$ concentrations at $\mathrm{pH} \mathrm{5}$, at four different temperatures $\left(5,10,15\right.$ and $\left.25^{\circ} \mathrm{C}\right)$. In agreement with previously published result on the complexation of $\mathrm{CA}$ by $\beta-\mathrm{CD}$ at neutral $\mathrm{pH}[1,13,14]$, Figure $2 \mathrm{a}$ shows that at $\mathrm{pH} 5$, the addition of $\beta$-CD to a CA solution increases its fluorescence intensity, producing at the same time, a small blue shift of the emission spectra (approximately $10 \mathrm{~nm}$ ). This behavior (both fluorescence intensity increase and emission spectra shift) has been observed when several phenolic compounds are complexed by cyclodextrins, and is attributed to the modification of the surrounding microenvironment of the phenolic moiety when it enters the hydrophobic cavity of the cyclodextrin $[1,5,15$, among others]. In this figure, it is also possible to observe that at high cyclodextrin concentrations, the fluorescence of the system remains practically unchanged, suggesting a saturation process commonly observed in complexation processes [1].

The stability constant, was determined by fitting the experimental fluorescence data at $437 \mathrm{~nm}$ for the different $\beta$ -

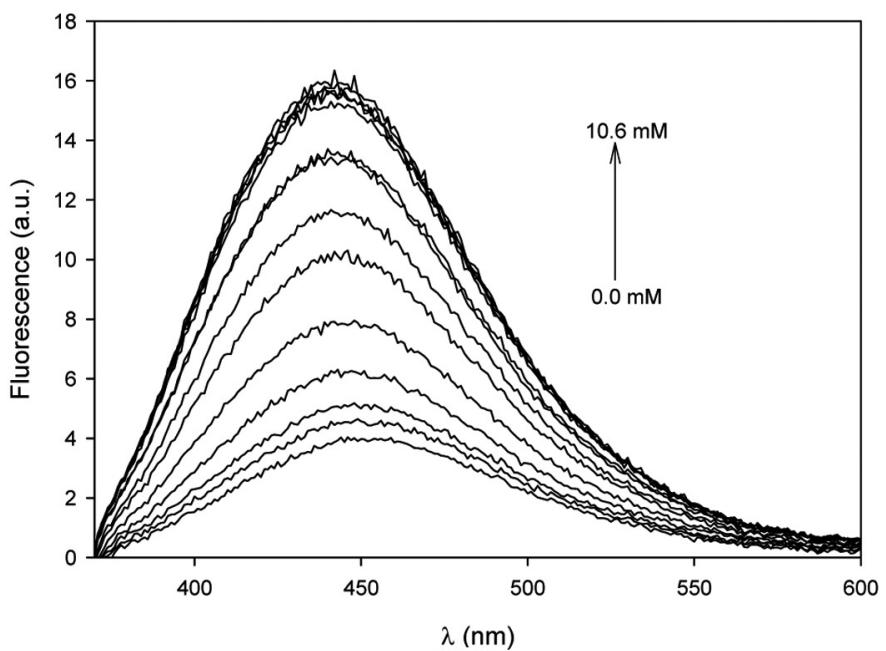

(a)

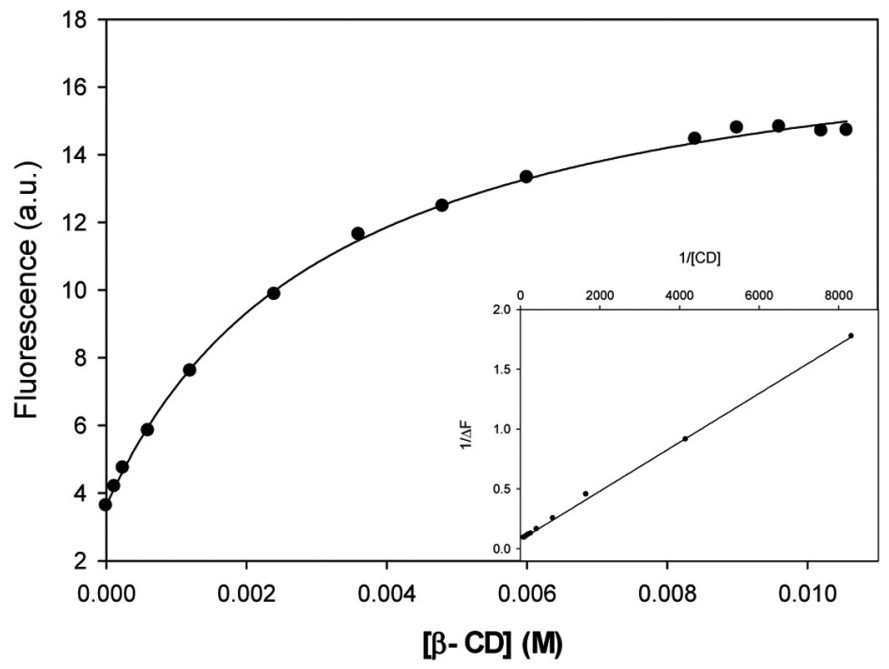

(b)

Fig. 2. (a) Emission fluorescence spectra of CA in the presence of different $\beta$-CD concentrations varying from zero to $10.6 \mathrm{mM}$. $\lambda_{\text {exc }}=320$ nm. $[\mathrm{CA}]_{0}=2.5 \cdot 10^{-5} \mathrm{M}$. pH 5.0 (Citrate buffer, final concentration $0.05 \mathrm{M}), 25 \pm 1{ }^{\circ} \mathrm{C}$. (b) Fluorescence intensities of CA at $437 \mathrm{~nm}$ versus different $\beta$-CD concentrations. Inset in (b): double reciprocal plot of the same data. Lines in (b) are the fitted curves to the experimental data.

$\mathrm{CD}$ concentrations to both linear and non-linear models (equations 5 and 6 ). Figure $2 \mathrm{~b}$ presents the experimental results (points) and fitted analysis (lines) of an experiment carried out at $25^{\circ} \mathrm{C}$. The inset if Figure $2 \mathrm{~b}$ represents the double reciprocal plot (Benesi-Hildebrand, eq. 5) of the experimental data. The straight line obtained from the regression analysis confirms the formation of a 1:1 stoichiometry complex between CA and $\beta-C D$, and the stability constant can be determined by dividing the slope against the intercept. Results presented in Table 1 show that, at all studied temperatures, the non-linear stability constants presented lower values, and were more accurate, compared to those obtained by the linear fitting. It has been 
reported that non-linear fitting gives better results because it minimizes the effect of errors, especially at low cyclodextrin concentrations [16]. When the stability constants obtained in the present work, at $25^{\circ} \mathrm{C},\left(351\right.$ and $207 \mathrm{M}^{-1}$ for the linear and non-linear analysis) are compared against those determined at $\mathrm{pH} 7$ with phosphate buffer (non-linear analysis, $465 \mathrm{M}^{-1}$ ) [1] or plain water (linear analysis, $424 \mathrm{M}^{-1}$ ) [13], it can be observed that the values at $\mathrm{pH} 5$ were smaller. These results can be explained in terms of the protonation degree of the CA molecule, at different $\mathrm{pH}$, since its $\mathrm{pKa}$ values are 3.33 [17] and 7.8-8.26 [18] for the carboxylic and hydroxyl groups from the quinic moiety, respectively. According to these values, at both pHs (7 and 5), the carboxylic group will be deprotonated, however, at $\mathrm{pH} 5$ the hydroxyl group close to the carbonyl group (quinic region) will be protonated, at $\mathrm{pH} 7$ it will be ionized. This difference in the protonation degree modifies the polarity of the CA molecule, and consequently its complexation behavior.

In order to determine the thermodynamic parameters of the system, the stability constants at four different temperatures $\left(5,10,15\right.$ and $\left.25^{\circ} \mathrm{C}\right)$ were determined, and are presented in Table 1. These relatively low temperatures were chosen in the present experiment considering that the technological applications for preventing browning of fresh-cut apples products are ideally carried out at temperatures near to $4^{\circ} \mathrm{C}$.

Figure 3 shows the Van't Hoff plots for the CA: $\beta-C D$ system determined using the linear and non-linear stability constants reported in Table 1. This figure shows a better linear correlation for the constants determined by non-linear fitting. $\Delta \mathrm{H}$ and $\Delta \mathrm{S}$ values are reported in Table 1 .

Figure 4 shows the raw (Figure 4a) and processed (Figure $4 \mathrm{~b})$ data obtained from $25 \mathrm{CA}$ injections into the ITC cell containing $\beta-\mathrm{CD}$ at $\mathrm{pH} 5 . \Delta \mathrm{H}$ and $\Delta \mathrm{S}$ values are presented in Table 1.

When the thermodynamic parameters listed in Table 1 are analyzed, it is possible to observe similar results for the

Table 1. 1:1 stability constants $\left(\mathrm{K}_{\mathrm{C} 1}\right)$, enthalpy and entropy change for the CA: $\beta$-CD complex, obtained by linear (Benesi-Hildebrand) and non-linear analysis of fluorescence data as a function of temperature (Figure 3), and by ITC experiments (Figure 4).

\begin{tabular}{cccc}
\hline Temperature & $\begin{array}{c}\text { Linear } \\
\text { fitting }\end{array}$ & $\begin{array}{c}\text { Non-linear } \\
\text { fitting }\end{array}$ & ITC $^{\mathrm{a}}$ \\
\hline $5^{\circ} \mathrm{C}$ & $663.5 \pm 140.4$ & $277.0 \pm 30.2$ & \\
$10^{\circ} \mathrm{C}$ & $504.3 \pm 34$ & $260.3 \pm 23.9$ & \\
$15^{\circ} \mathrm{C}$ & $390.8 \pm 65.6$ & $253.2 \pm 26.7$ & \\
$25^{\circ} \mathrm{C}$ & $351.2 \pm 69$ & $207.0 \pm 17.4$ & 442 \\
$\Delta \mathrm{H}^{\mathrm{b}}$ & -25.5 & -11.7 & -12.9 \\
$\Delta \mathrm{S}^{\mathrm{c}}$ & -37.61 & 5.12 & 7.45 \\
$\mathrm{r}^{2}$ & 0.885 & 0.948 & \\
\hline
\end{tabular}

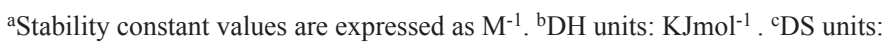
$\mathrm{Jmol}^{-1} \mathrm{k}^{-1}$

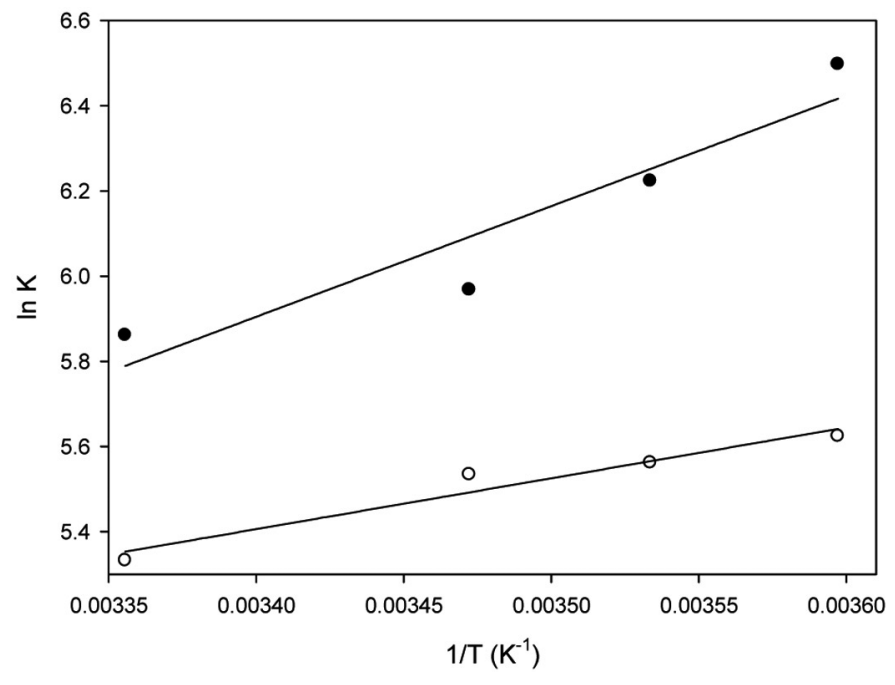

Fig. 3. van't Hoff plots for the CA- $\beta-C D$ system, using the linear $(\bullet)$ and non-linear ( ) stability constants values.

constants obtained by the non-linear fitting of the fluorescence spectroscopic data, with those obtained by ITC. The negative $\Delta \mathrm{H}$ and positive $\Delta \mathrm{S}$ values suggest that the complexation of CA by $\beta-C D$ is an enthalpy-driven process, in which hydrogen bond and van der Waals forces are the main rolling forces of the process. These results are in agreement with those reported by Górnas and Irwin $[13,19]$ at $\mathrm{pH} 7$.

Interestingly, when the stability constants are compared, we observed that the ITC constant was higher than those obtained by the non-linear fitting, and similar to the ones reported at $\mathrm{pH} 7[1,13,14,19]$. These results suggest that in the CA: $\beta$-CD system, a more complex process than the entrapment of the phenolic moiety in the interior of the CD cavity is taking place.

\section{Cyclic voltammetry}

Cyclic voltammetry experiments of different $\beta$-CD: CA ratios were carried out at $\mathrm{pH} 5$, and results are shown in Figure 5. At all CD concentrations, CA behaved as a reversible redox system. The cyclic voltammogram for the free CA showed a peak potential of approximately $400 \mathrm{mV}$ vs. SCE, similar to the one reported by Namazian (2005) for CA at pH 5 [18]. The redox potential shift only shifts slightly in our experimental conditions indicating a low affinity of $\mathrm{CD}$ with the redox moiety (cathecol) (Figure 5B). In the other hand the current value decreases continuously with the addition of CD (Figure 5C). A first explanation can be attributed to the diffusion coefficient decrease of the redox molecule due to the complex formation [20]. The reversible system observed without $C D$ does not change its general patron with the addition of $\mathrm{CD}$, indicating that the electrooxidation-reduction process occurs via the clasical mechanism ECEC reported previously in aqueous media quinone-hydroquinone [21] 


\section{Time (min)}

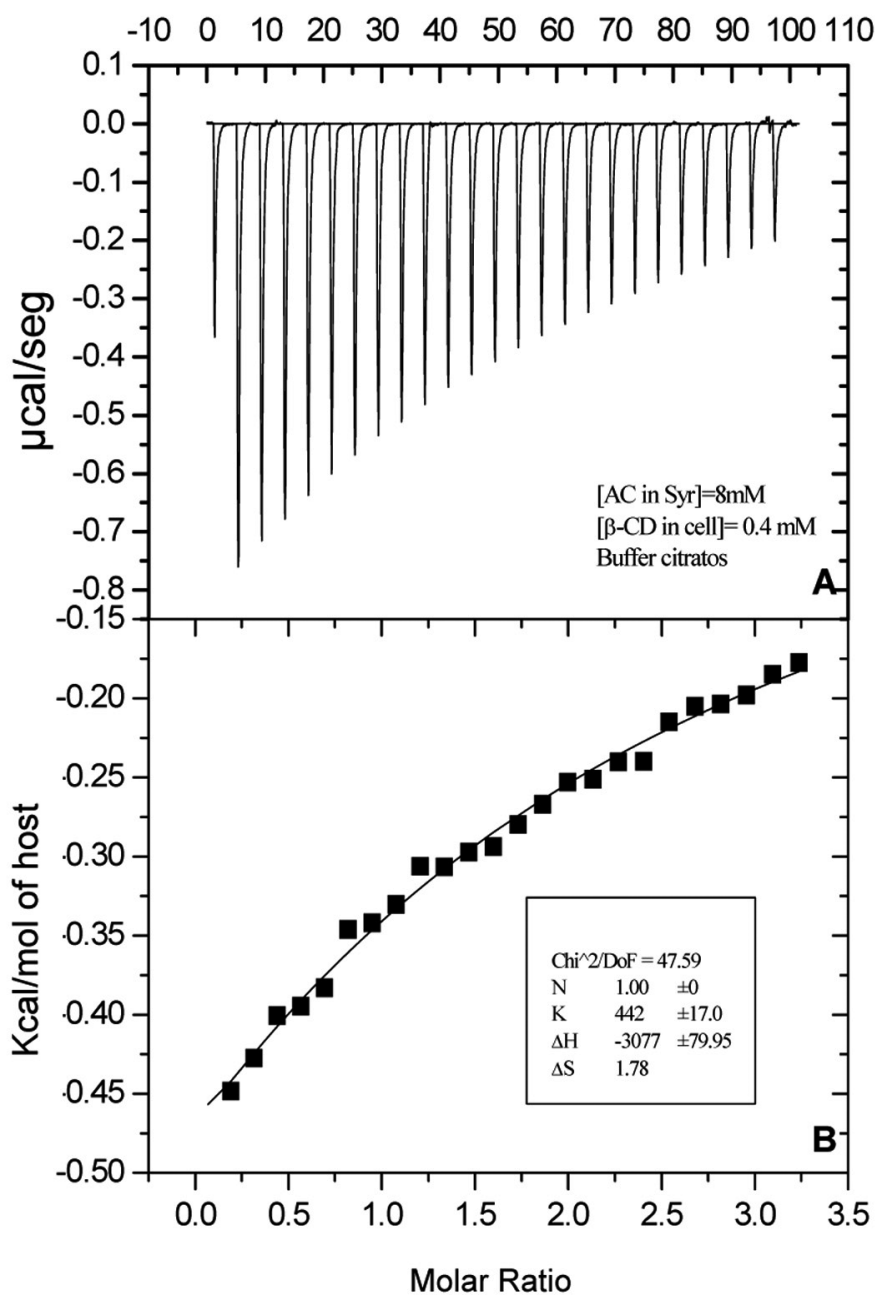

Fig. 4. Calorimetric titration of $\mathrm{CA}$ with $\beta-\mathrm{CD}$ in $0.05 \mathrm{M}$ citrate buffer $(\mathrm{pH} 5)$ at $25^{\circ} \mathrm{C}$. (A) Raw data of sequential 25 injections of $9 \mu \mathrm{L}$ of CA solution ( $8 \mathrm{mM})$ into the $\beta-\mathrm{CD}(0.4 \mathrm{mM})$. (B) Heats of reaction and thermodynamic parameters obtained from the integration of the calorimetric traces, after correction for CD heat of dilution.
This effect was temperature dependent, being more evident the current changes at low temperatures, due to the viscosity increase and its effect on the diffusion coefficient of the complex CA-CD. Even when a change on the redox signal potential was expected, due to the complexation of the catechol moiety (redox function), in the present study, no significant and systematic shift was observed (Figure 5b). An explanation to this behavior is that $\mathrm{CD}$ complexes preferentially at all experimental conditions, the quinic moiety (QC complex) that has not redox properties, in other experimental conditions, catechol moiety (CC complex) could also be complexed (see Fig. 6). This process would form two different 1:1 complexes depending on the experimental conditions. Both complexes would modify the diffusion coefficient of the CA, but only the catechol complexation would affect the peak potential.

\section{ROESY measurements}

The ${ }^{1} \mathrm{H}$ NMR chemical shift observed for the free and complexed CA, showed a downfield displacement of the ${ }^{1} \mathrm{H}$ signals from both phenolic and quinic moieties, suggesting the complexation of both regions [21]. In order to better understand the complexation process that is occurring between CA and $\beta-C D$, ROESY experiments were carried out. ROESY is a two dimensional technique, based on the nuclear Overhauser effect, in which cross-peaks interactions are observed between protons if their internuclear distance is smaller than 3-4 $\AA$, which has been used in order to determine the structure of cyclodextrin complexes [22].

Crosspeak interactions between protons $\mathrm{H}-3, \mathrm{H}-5$ and $\mathrm{H}-6$ of $\beta-\mathrm{CD}$ with CA protons (P-n, where $\mathrm{n}$ is the carbon number indicated in Figure 1b) are summarized in Table 2.

The following statements can be extracted from Table 2 analysis: a) H-3 (weak) and H-5 (strong) are interacting with protons form the phenolic ring, b) weak interactions are observed between $\mathrm{H}-3$ and $\mathrm{H}-5$ with protons $\mathrm{P}-2, \mathrm{P}-4$ and P-6 from the quinic moiety, c) H-6 interacts with protons P-2 (strong), P-5 (weak) and P-6 (strong) from the quinic
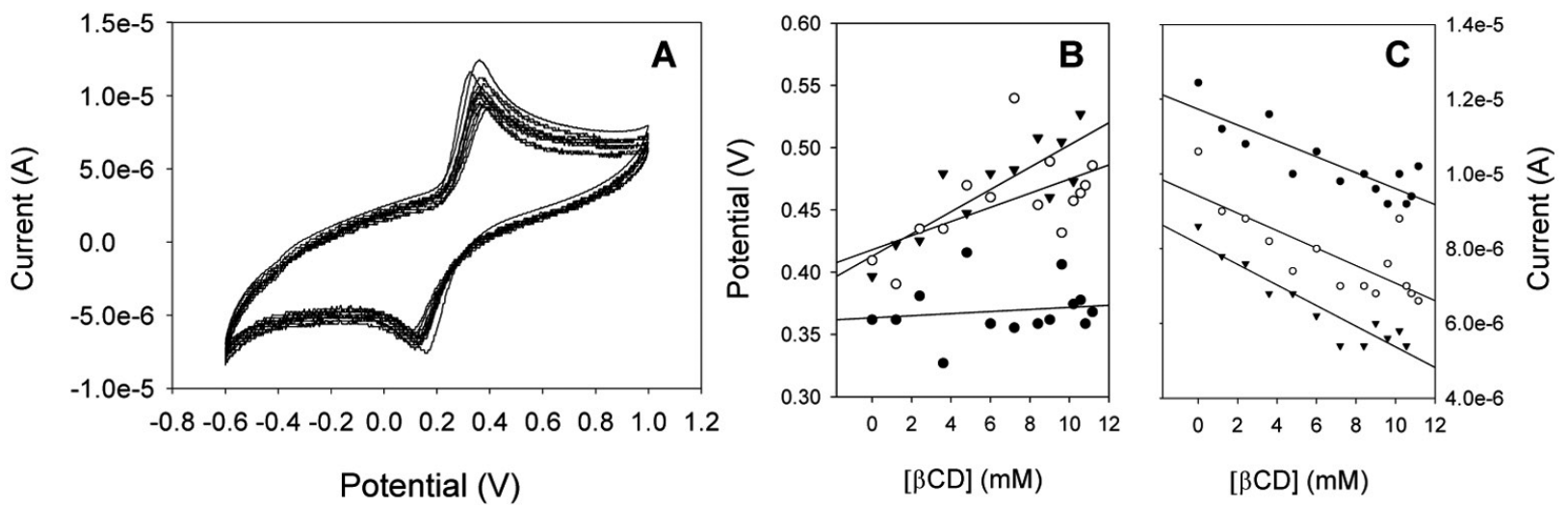

Fig. 5. (A) Cyclic voltamperograms of $\mathrm{CA}\left(5 \cdot 10^{-4} \mathrm{M}, \mathrm{pH} 5\right.$, citrate buffer $0.05 \mathrm{M}$ ) in the presence of different $\beta$-CD concentrations (from 0 to $11.16 \mathrm{mM})$. Effect of temperature $\left(25^{\bullet}, 10\right.$ and $\left.5^{\circ} \mathrm{C} \boldsymbol{\nabla}\right)$ on $(\mathrm{B})$ Anodic potential and (C) Anodic peak. 
Table 2. ROESY Intermolecular Cross Peak interactions observed between protons $\mathrm{H}-3, \mathrm{H}-5$ and $\mathrm{H}-6$ of $\beta-\mathrm{CD}$ and $\mathrm{CA}$ protons, obtained in the ROESY experiment $(*$, weak: **, medium: *** strong interactions).

\begin{tabular}{cccc}
\hline & \multicolumn{3}{c}{$\beta-\mathrm{CD}$} \\
\cline { 2 - 4 } CA & $\mathrm{H}-3$ & $\mathrm{H}-5$ & $\mathrm{H}-6$ \\
\hline $\mathrm{P}-2$ (a,b) & $*$ & $*$ & $* * *$ \\
P-3 & & $*$ & \\
P-4 & $*$ & $*$ & $* *$ \\
P-5 & & & \\
P-6 (a,b) & $*$ & & \\
P-7 & & $* * *$ \\
P-8 & & $* * *$ & \\
P-2 & $*$ & & \\
P-5 & & & \\
\hline
\end{tabular}

moiety, d) no interactions where observed with protons from the aliphatic region. Moreover both steady-state fluorescence spectroscopy and isothermal titration calorimetry confirmed the formation of $1: 1$ stoichiometry complexes, but not of a 2:1 stoichiometry complex $(\beta-\mathrm{CD}: \mathrm{CA})$. Therefore it can be deduced that the complexation of $\mathrm{CA}$ by $\beta-\mathrm{CD}$, involves the simultaneous formation of two different 1:1 complexes, resulting from the complexation of the catechol moiety (CC complex) or the quinic moiety (QC complex) into a CD cavity (Figure 6). These results are in agreement with those obtained by cyclic voltammetry.

If we consider the ITC constant as the macroscopic (global) constant of the system $\left(\mathrm{K}_{11}, 442 \mathrm{M}^{-1}\right)$, which involves the two microscopic stability constants for the two complexes formed, according to eq. $1[16,23,24]$ :

$$
\mathrm{K}_{11}=\mathrm{K}_{1 \mathrm{CC}}+\mathrm{K}_{1 \mathrm{QC}}
$$
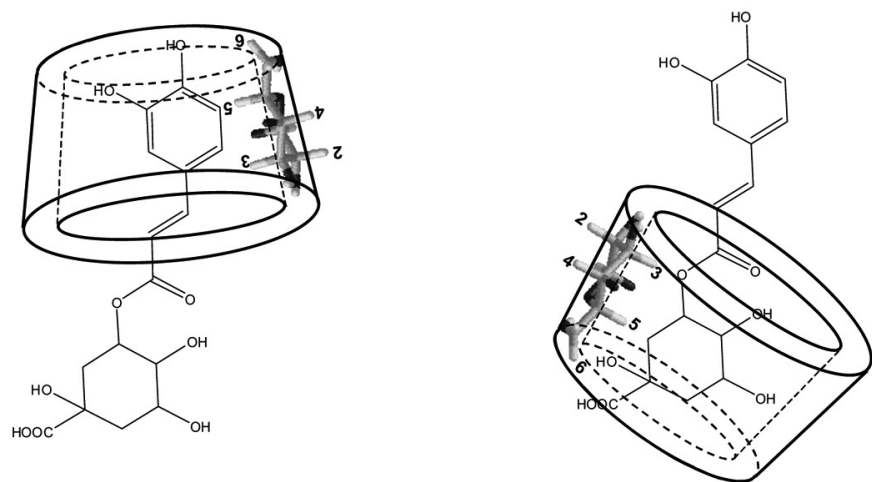

Fig. 6. Schematic representations of the two different 1:1 CA: $\beta-C D$ complexes deduced from ROESY cross-peak interactions shown in table 1. (a) Catechol- $\beta$-CD complex (CC-complex) (b) Quimic acid $-\beta-C D$ complex (QC-complex)
Where $\mathrm{K}_{1 \mathrm{CC}}$ is the microscopic stability constant of the catechol moiety and $\mathrm{K}_{1 \mathrm{QC}}$ means the microscopic stability constant of the quinic moiety involved in the two different complexes formation. The stability constant of the quinic moiety, which is not fluorescent, can be deduced considering that the stability constant calculated by fluorescence spectroscopy is the one for the phenolic moiety $\left(207 \mathrm{M}^{-1}\right)$. According to this argument, the quinic moiety constant presents a value of 235 $\mathrm{M}^{-1}$, a value similar to the one obtained by fluorescence for the phenolic moiety $\left(207 \mathrm{M}^{-1}\right)$.

If we consider the overall equilibrium according to eq. 1 , the initial concentration of $\mathrm{CD}$ and $\mathrm{CA}$, will depend on the concentration of the free molecules as well as the concentration of both complexes (ie. initial CD: $[\mathrm{CD}]_{0}=[\mathrm{CD}]+\mathrm{C}_{1 \mathrm{CC}}$ $\left.+\mathrm{C}_{1 \mathrm{PC}}\right)$, under the experimental conditions described in the experimental section, both microscopic constants can be determined using Eq. 2 [16]:

$$
F^{\lambda}=\frac{F_{H}^{\lambda}\left(F_{C 1 C C}^{\lambda} \frac{K_{1 C C}}{K_{11}}+F_{C 1 Q C}^{\lambda} \frac{K_{1 Q C}}{K_{11}}\right) K_{11}[C D]_{0}}{1+\left(K_{1 C C}+K_{1 Q C}\right)[C D]_{0}}
$$

Where $F_{C 1 C C}^{\lambda}$ and $F_{C 1 Q C}^{\lambda}$ are the fluorescence of the catechol and quinic moieties, and $[\mathrm{CD}]_{0}$ is the initial $\mathrm{CD}$ concentration. Considering the ITC constant as the macroscopic constant of the system $\left(\mathrm{K}_{11}, 442 \mathrm{M}^{-1}\right), \mathrm{K}_{1 \mathrm{CC}}$ and $\mathrm{K}_{1 \mathrm{QC}}$ were determined by fitting the fluorescence experimental values at $25^{\circ} \mathrm{C}$, for each $\mathrm{CD}$ concentration to Eq. 2. The $\mathrm{K}_{1 \mathrm{CC}}$ and $\mathrm{K}_{1 \mathrm{QC}}$ values obtained were 220 and $93 \mathrm{M}^{-1}$, respectively. When we compare these values, to the previous once, it is possible to observe that $\mathrm{K}_{1 \mathrm{QC}}$ has a lower value; however, $\mathrm{K}_{1 \mathrm{CC}}$ is quite similar. These results suggest that, even though both 1:1 complexes will form, the complexation of the catechol moiety is more favored.

From all the above results the following conclusions can be drawn: a) The complexation of $\mathrm{CA}$ by $\beta-\mathrm{CD}$ is an enthalpy-driving process, this has some important technological implications because it means that at low temperatures CA is more tightly complexed; b) at slightly acidic $\mathrm{pH}$, when the hydroxyl group at the quinic moiety is protonated, two different 1:1 complexes (CC and QC), with similar stability constants, are formed. Comparing our results to those recently published by Górnas [13], it is probable that $\mathrm{pH}$ regulates the way in which CA is complexed, in this way, at neutral $\mathrm{pH}$, where both carbonyl and hydroxyl groups from the quinic moiety are deprotonated, only the phenolic moiety would be complexed.

Finally, when the inhibition effect of $\beta-\mathrm{CD}$ over the PPO activity was recalculated using the experimental data published in reference [8], and considering the stability constant determined at $\mathrm{pH} 5$ in the present paper (data not shown), we could observe once again an inhibition on its activity. This results support the hypothesis that $\beta-\mathrm{CD}$ inhibits PPO by a mechanism additional to substrate complexation. However, in 
order to proof this hypothesis, further studies on the complexation of the CA quinone and direct PPO- $\beta-C D$ interaction need to be developed.

\section{Experimental}

Materials. Chlorogenic acid (1,3,4,5-tetrahydroxycyclohexane carboxylic acid 3-[3,4-dihydroxycinnamate]) was purchased from Sigma (USA). $\beta$-cyclodextrin (Kindly supplied by Wacker Biohem, USA) was recrystallized twice from distilled water, dried in a vacuum oven over anhydrous phosphorus pentoxide. Citrate buffer $(\mathrm{pH} \mathrm{5}$, final concentration 0.05 $\mathrm{M})$ was prepared from citric acid and sodium citrate, all from Jalmek A.C.S. grade (Mexico). All other reagents used were A.C.S grade from Acrôs Organics (USA).

Fluorescence measurements. Steady-state fluorescence measurements were performed with a Shimadzu RF 5301 PC spectrofluorometer (Shimadzu Scientific Instruments, USA). All emission spectra were recorded using $5 \mathrm{~nm}$ excitation and emission slits. Stability constants were determined according to the methodology described by Alvarez-Parrilla (2005) with slight modifications [1]. Briefly, a $10^{-4} \mathrm{M}$ CA water stock solution was daily prepared and kept protected from light. From these stock solution, samples for fluorescence measurement were prepared just before the measurement, with a final CA concentration of $2.5 \cdot 10^{-5} \mathrm{M}$. $0.012 \mathrm{M} \beta-\mathrm{CD}$ stock solution in water was prepared and different $\mathrm{CD}$ concentrations were used in the range of $2.5 \cdot 10^{-4}$ to $1 \cdot 10^{-2} \mathrm{M}$. The $\mathrm{pH}$ of these solutions was adjusted to 5.0 by adding citrate buffer (Total citrate concentration: $0.05 \mathrm{M}$ ). All samples were kept $15 \mathrm{~min}$ at the experimental temperature $\left(5,10,15\right.$ and $\left.25^{\circ} \mathrm{C}\right)$ protected from light before measurement. Emission fluorescence spectra were acquired in the $365-600 \mathrm{~nm}$ interval, at a fixed excitation wavelength of $320 \mathrm{~nm}$.

The stability constants of the complexes formed between $\beta-C D$ and the CA were determined from the fluorescence experimental data recorded, assuming the following equilibrium [16]:

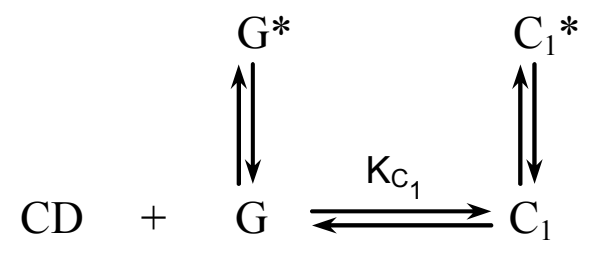

Where $\mathrm{G}^{*}$ and $\mathrm{Cl}^{*}$ are the guest and the complex in the excited state, they are the only fluorescent species, and that there is no association or dissociation process in the excited state. $\mathrm{K}_{\mathrm{C} 1}$ is the stability equilibrium constant, for the system, defined as a function of the equilibrium concentrations of the three species present in the system:

$$
K_{C_{1}}=\frac{\left[C_{1}\right]}{[C D] \cdot[G]}
$$

Under the experimental condition previously described, in which the $\mathrm{CD}$ concentration is much higher (more than 10 times, for the lowest CD concentration) than the initial CA concentration, it is possible to assume that the initial CD concentration is approximately the same than that of free $\mathrm{CD}$, after reaching the equilibrium, and the stability constant of the system can be determined by fitting the experimental fluorescence intensity at any wavelength (Fl) to the initial CD concentration $\left([\mathrm{CD}]_{0}\right)$ using a linear (Eq. 5, BenesiHildebrand) or non linear method (Eq 6). For a complete description of the derivation of these equations see references $[16,23]$ In the present work, the working wavelength was $437 \mathrm{~nm}$ :

$$
\begin{aligned}
\frac{1}{\Delta F} & =\frac{1}{\Delta F_{c}}+\frac{1}{K_{C 1} \Delta F_{c}[C D]_{0}} \\
F^{\lambda} & =\frac{F_{H}^{\lambda}+F_{C 1}^{\lambda} K_{1}[C D]_{0}}{1+K_{C 1}[C D]_{0}}
\end{aligned}
$$

Where $F_{H}^{\lambda}$ and $F_{C 1}^{\lambda}$ are the fluorescence intensities at any wavelength for the free and complexed $\mathrm{CA}, \Delta \mathrm{F}$ is the difference on fluorescence between free guest, and $\mathrm{DF}_{\mathrm{c}}$ is the difference on fluorescence between free guest and 1:1 complex. Eq. 5 was fitted in excel, and Eq. 6 using a commercial nonlinear least-squares fit program (SIGMA PLOT 8.0), using as initial parameters $\left(\mathrm{K}_{\mathrm{C} 1}\right.$ and $\left.F_{C 1}^{\lambda}\right)$ those obtained from the linear analysis of the experimental data (Eq. 5) [23].

Thermodynamic parameters (DH, DS and DG) were determined by fitting the 1:1 stability constants determined at different temperatures to the van't Hoff equation (Eq. 7):

$$
\ln K=-\frac{\Delta H}{R T}+\frac{\Delta S}{R}
$$

\section{Isothermal Titration Calorimetry (ITC) Measurements}

Calorimetric titrations were performed with a VP-ITC calorimeter from Microcal Inc., Northampton, MA., USA. CA and $\beta-\mathrm{CD}$ were prepared in citrate buffer $\mathrm{pH} 5$, with a $0.05 \mathrm{M}$ final concentration. Samples were degassed in a ThermoVac accessory before titration. Initially, the dilution heats for both $\mathrm{AC}$ and $\beta-\mathrm{CD}$ were determined injecting $8 \mathrm{mM}$ and $12 \mathrm{mM}$ solutions of $A C$ and $\beta-C D$, respectively into citrate buffer. For this, 25 injections $(9 \mu \mathrm{L})$ of host $(\mathrm{CD}$ or $\mathrm{AC}$, depending on the 
experiment) were injected with stirring at $300 \mathrm{rpm}$ into the reaction cell $(1.4227 \mathrm{~mL})$ charged with the buffer solution of guest ( $\mathrm{CD}$ or $\mathrm{CA})$. The first point was excluded from the fitting procedure, but the titrant added in the first injection was included in calculating the total amount of titrant in the solution [25]. Since $\beta-C D$ dilution heat was not negligible, it was taken in count for the final calculations. Two sets of experiments were performed. In the first one, CA solution $(8 \mathrm{mM})$ was injected to a $\beta$-CD solution $(0.4 \mathrm{mM})$, and in the second experiment, $\beta$-CD $(12 \mathrm{mM})$ was injected into the reaction cell filled with CA $(1 \mathrm{mM})$.

The equilibrium constant $\left(\mathrm{K}_{\mathrm{C} 1}\right)$, enthalpy of reaction $(\Delta \mathrm{H})$ and change of entropy $(\Delta S)$ were simultaneously determined, by fitting the heat of reaction data to a 1:1 stoichiometry model (Eq 2 and 3) according to Eq. 8, using ORIGIN software (Microcal Inc.):

$$
\frac{d Q}{d H_{t}} \cdot \frac{1}{V_{0}}=\Delta H^{0}\left(\frac{1}{2}+\frac{1-(1+r) / 2-H_{r} / 2}{\left(H_{r}^{2}-2 H_{r}^{2}(1-r)+(1+r)^{2}\right)^{1 / 2}}\right)
$$

Where dQ is the heat change, $\mathrm{dH}_{\mathrm{t}}$ is the host concentration change, and $\mathrm{r}$ and $\mathrm{H}_{\mathrm{r}}$ are expression that describe the total host and guest concentration at every moment [25].

\section{Cyclic Voltammetry (CV) Measurements}

CV experiments were performed on a $273 \mathrm{~A}$ potentiostat (Princeton Applied Research). A $1 \mathrm{~cm}^{2}$ polished glassy carbon was used as working electrode, a $\mathrm{KCl}$-saturated calomel electrode as reference electrode and a Pt wire as counter electrode. Measurements were recorded between -600 to $1000 \mathrm{mV}$, at a sweep rate of $100 \mathrm{mVs}^{-1}$. The electrochemical cell was thermostated at $25^{\circ} \mathrm{C}$ with a circulating water bath. Samples were degassed with GC-grade $\mathrm{N}_{2}$. All experiments were carried out using a citrate buffer solution at $\mathrm{pH} 5$ and final concentration of $0.05 \mathrm{M}$. CA was used at a final concentration of $5 \cdot 10^{-4} \mathrm{M}$ Different $\beta$-CD concentrations in the range of 0 to $11.16 \mathrm{mM}$ were used.

\section{ROESY measurements}

ROESY experiments were recorded on a Varian Inova system at $500 \mathrm{MHz}$, using the standard ROESY experimental conditions. Two experiments were carried out, at 1:1 and 1:3 CA: $\mathrm{CD}$ ratios concentrations. $\mathrm{CA}$ and $\beta$-CD NMR signals were previously assigned in separate ${ }^{1} \mathrm{H}$ NMR experiment, and according to published results $[21,26]$.

Statistical analysis. Stability constant values represent the mean \pm SEM of three replicates. ITC experiments were carried only one time.

\section{Acknowledgements}

Financial supports from UACJ (internal projects) and CONACYT, México (STU1-2008-102083) are gratefully acknowledged. R.P. thanks CONACYT (México) for a bachelor degree scholarship and Academia Mexicana de Ciencias for a Summer Research Grant. We thank Dr. María Isabel Chávez (Instituto de Química de la UNAM) for NMR determinations.

\section{References}

1. Alvarez-Parrilla, E.; de la Rosa, L. A.; Torres-Rivas, F.; RodrigoGarcía, J; González-Aguilar, G. A. J. Inclusion Phenom. Macrocycl. Chem. 2005, 53, 121-129.

2. Hertog, M. G.; Kromhout, D.; Aravanis, C.; Blackburn, H.; Buzina, R.; Filanza, F.; Giampaoli, S.; Cansen, A.; Menotti, A.; Nedeljkovic, S. Arch. Intern. Med. 1995, 155, 381-386.

3. Jullian, C.; Orosteguis, T.; Pérez-Cruz, F.; Sánchez, P.; Mendizábal, F.; Olea-Azar, C. Spectrochim. Acta A. 2008, 71, 269-275.

4. Mourtzinos, I.; Makris, D. P.; Yannakopoulou, K.; Kalogeropoulos, N.; Machali, I.; Karathanos, V. T. J. Agric. Food Chem. 2008, 56, 10303-10310.

5. Lucas-Abellán, C.; Fortea, I.; Gabaldón, J. A.; Núñez-Delicado, E. J. Agric. Food Chem. 2008, 56, 255-259.

6. López-Nicolas, J. M.; Garcia-Carmona, F. J. Agric. Food Chem. 2007, 55, 6330-6338.

7. López-Nicolas, J. M.; Pérez-López, A.; Carbonell-Barrachina, A.; Garcia-Carmona, F. J. Agric. Food Chem. 2007, 55, 5312-5319.

8. Alvarez-Parrilla, E.; de la Rosa, L.A.; Rodrigo-Garcia, J.; Escobedo-Gonzalez, R.; Mercado-Mercado, G.; Moyers-Montoya, E.; Vazquez-Flores, A.; Gonzalez-Aguilar, G.A. Food Chem. 2007, 101, 1346-1356.

9. Queiroz, C.; Mendes Lopes, M. L.; Fialho, E.; Valente-Mequita, V. L. Food Rev. Int. 2008, 24, 361-375.

10. Gacche, R. N.; Zore, G. B.; Ghole, V. S. J. Enz. Inh. Med. Chem. 2003, 18, 1-5.

11. Casado-Vela, J.; Selles, S.; Bru, R. J. Food Biochem. 2006, 30, 623-640.

12. Fayad, N.; Marchal, L.; Billaud, C.; Nicolas, J. J. Agric. Food Chem. 1997, 45, 2442-2446.

13. Górnas, P.; Neunert, G.; Baczyñski, K.; Polewski, K. Food Chem. 2009, 114, 190-196.

14. Rodrigues, E.; Vaz, S.; Gil, V. M. S. S.; Caldeira, M. M.; Moreira de Silva, A. M. G. J. Inclusion Phenom. Macroxyclic Chem. 2002, 44, 395-397.

15. Shuang, S.-M.; Pan, J-H.; Guo, S.-Y.; Cai, M.-Y.; Liu, C.-S. Anal. Lett. 1997, 30, 2261-2270.

16. Alvarez-Parrilla, E.; Al-Soufi, W.; Ramos Cabrer, P.; Novo, M.; Vázquez Tato, J. J. Phys. Chem. B. 2001, 105, 5994-6003.

17. de Bôer, G.; Hanson, F. E. Entomol. Exp. Appl. 1987, 45, 123131.

18. Namazian, M.; Zare, H. R. Electrochim. Acta. 2005, 50, 43504355.

19. Irwin, P.; Brouillette, J.; Giampa, A.; Hicks, K.; Gering, A.; Tu, S.-I. Carbohyd. Res. 1999, 322, 67-76.

20. Chen, M.; Diao, G.; Zhang, E. Chemosphere 2006, 63, 522-529.

21. Bailey, S. I.; Ritchie, I. M. Electrochim. Acta 1985, 30, 3-12

22. Ramos Cabrer, P.; Alvarez-Parrilla, E.; Meijide, F.; Seijas, J. A.; Rodríguez Núñez, E.; Vázquez Tato, J. Langmuir 1999, 15, 54895495.

23. Connors, K.A. Binding Constants: The Measurement of Molecular Complex Stability. John Wiley and Sons, Inc.: USA. 1987. 
24. Jover, A.; Budal, R. M.; Meijide, F.; Soto, V. H.; Vázquez Tato, J. J. Phys. Chem. 2004, 108, 18850-18859.

25. Wiseman, T.; Williston, S.; Brandts, J. F.; Lin, L. N. Anal. Biochem. 1989, 179, 131-137.
26. Kono, Y.; Kashine, S.; Yoneyama, T.; Sakamoto, Y.; Matsui, Y.; Shibata, H. Biosci. Biotechnol. Biochem. 1998, 62, 22-27. 